\title{
A lean case study in an oncological hospital: implementation of a telephone triage system in the emergency service
}

This article was published in the following Dove Press journal:

Risk Management and Healthcare Policy

9 December 2013

Number of times this article has been viewed

\section{José Crespo de Carvalho' Madalena Ramos' Carina Paixão}

'Business School, University Institute of Lisbon, Lisbon, Portugal; ${ }^{2}$ Instituto Português de Oncologia, Lisbon, Portugal
Correspondence: José Crespo de Carvalho University Institute of Lisbon,

Av das Forças Armadas, 1649-026 Lisbon, Portugal Tel +35I 938457900 Email crespo.carvalho@gmail.com; crespo.carvalho@iscte.pt
Abstract: Lean practices and thinking have increased substantially in the last few years. Applications of lean practices to health care are found worldwide. Despite that, new contributions are required because the application of lean thinking to hospitals has a long way to go. Lean practices and thinking do not include, in the literature or practice programs, any references to triage systems in health care units. The common triage systems require physical presence, but there are alternative methods to avoid the need to move patients: these alternative triage systems, given their characteristics, may be included in the spectrum of lean practices. Currently, patients that are already known to suffer from cancer are encouraged to go to hospital (public or private, with an oncological focus) when facing side effects from chemotherapy or radiation treatments; they are then submitted to a triage system (present themselves to the hospital for examination). The authors of this paper propose the introduction of telephone or email triage for impaired patients as a valid substitute for moving them physically, thereby often avoiding several unnecessary moves. This approach has, in fact, characteristics similar to a lean practice in that it reduces costs and maintains, if done properly, the overall service offered. The proposed 'remote' triage emerged from the results of a large survey sent to patients and also as the outcome of a set of semistructured interviews conducted with hospital nurses. With the results they obtained, the authors felt comfortable proposing this approach both to public and private hospitals, because the study was conducted in the most important, largest, and best-known oncological unit in Spain. As a final result, the health care unit studied is now taking the first steps to implement a remote triage system by telephone, and has begun to reduce the previously necessary movement of impaired patients.

Keywords: lean health care, lean practices, emergency department, telephone/remote triage

\section{Introduction}

Lean management has gained acceptance in recent years, mainly because it involves a cost-reduction focus while concurrently attempting to maintain the value offered to the customer. ${ }^{1}$ Almost any sector or activity can apply lean management principles. Health care systems and units have not escaped the lean management focus, or from the potential of savings while trying to maintain service to patients. ${ }^{2-4}$ The objective of this paper is to present the benefits of a remote triage system - a telephone and/or email triage system - as applied to the emergency service of an oncological hospital. The benefits would be to avoid physically moving impaired patients, to reduce costs, and to improve patient care/service. These benefits are supported by an empirical approach and also corroborated by the internal collaborators of the hospital - the nurses who work in triage systems. 
In this study, we developed a case study structure with both qualitative and quantitative evaluations based on empirical primary data, drawn from semistructured interviews with nurses for the qualitative approach and from patient questionnaires for the quantitative approach. Our goals were to study in depth and to evaluate the applicability of a telephone and an email triage system that could satisfy an increasing number of patients and, in parallel, the scarcity of collaborators. The study was conducted to obtain answers from two different types of stakeholders, patients as clients; and nurses as triage collaborators. Regarding patients, the study attempted to evaluate the potential reduction of certain instances where the patient would be moved physically, and also time spent in the system. Regarding the hospital, our goal was to anticipate the effects of the new triage system (by telephone and/or email) as a possible lean element and to incorporate some of the principles developed in this paper. For these reasons, it was necessary to gather information by means of a survey that was conducted using semistructured interviews with health care professionals and also applying questionnaire techniques to the patients. With this approach, the present authors endorsed a hybrid methodology, in part interpretivist and in part positivist. The study methods were both descriptive/qualitative and quantitative, as it will be explored in a later section of this paper.

The organization chosen is regarded as a landmark institution and is the central health care public hospital at the national level of Spain for treatment of oncological illnesses. Figures and the average data for the period between 2011 and 2013 illustrate the scale of the institution: 285 beds, with an occupancy rate of $78.23 \%$; 1,932 employees distributed among 35 specialized units; 212,132 medical appointments and 6,937 surgical procedures; and an average of 32,232 patient registrations per year during the above-mentioned period. Careful inspection of the data regarding patient care in this specific emergency facility in recent years reveals a significant increase in the number of admissions. The average number of daily admissions in 2006 was 21.7 patients per day, totalling 7,928 patients per year; in 2012 this figure was 24.5 patients per day, totalling 8,929 patients per year, of which 2,114 patients were hospitalized and the remaining 6,815 advised to return home or referred to other institutions. However, this increase in the number of patients was not accompanied by a corresponding increase in staff and physical or material infrastructure, resulting in a discrepancy between the inflow of patients and the capacity to efficiently meet their needs. This situation leads to a reduction in the quality of care provided and patient satisfaction with the service.

\section{Lean management approaches in health care systems}

Lean management systems were developed some years ago and have evolved substantially since the first years when they were applied at Toyota. ${ }^{5}$ The principles are based on 1) value specification; 2) identifying value streams; 3) continuous value development and making value create flow; 4) maintaining the system driven by customers (internal and external to the system); and 5) striving for perfection. ${ }^{5-8}$ This approach has delivered good results, and the implementation in health care systems has offered substantial benefits that include cost reduction and an increased quality of care. ${ }^{2,3,6}$ Patient flows and organization of trajectories in health care systems, both of patients and of organization collaborators, demanded some benefits from the lean approach perspective, especially to eliminate waiting lines, excessive amounts of physically moving the patients, and wasted time..$^{9,10}$ Lean approaches are more and more common in emergency services and, even if indirectly, triage systems will need enablers and/or lean management facilitators. ${ }^{11-14}$ In line with this reasoning, reducing the amount of time patients spend in the health care facility is critical and motivates some planning and integration of activities. ${ }^{15,16}$ If the space available at the health care unit is constantly evaluated as being insufficient and the number of health care professionals is insufficient to serve the patients, lean management principles should be used to find solutions. There are two sets of practices that should be re-evaluated and/or redesigned. ${ }^{1,10,17-20}$ First, these six issues must be confronted: 1) sorting; 2) setting in order; 3) systematic cleaning; 4) standardizing; 5) servicing; and 6) improving security. Next, the waste-avoidance approach must be taken, ${ }^{1,2}$ which includes grappling with seven issues: 1) overproduction - too much or too soon; 2) defects and frequent errors; 3) unnecessary inventory, excessive storage, and delay of information about pharmaceuticals and consumables; 4) inappropriate processing - using the wrong set of tools, procedures or systems; 5) excessive transportation - excessive movement of people, information, or goods; 6) waiting - long periods of inactivity followed by intense periods of activity; and 7) unnecessary motions - poor workplace organization of health care facilities.

Alternatively, or in parallel, the guidance provided by the following eight principles of the lean management philosophy would balance the available space with the scarcity of human resources in health care services: 1) the purpose 
of each activity should be aligned with the overall purpose of the organization; 2) considering all the processes, direction, core or enabling processes, 3) personnel, an area often misunderstood in lean management and that should include leadership, 4) pull, including pull-based delivery, pull improvement, and pull based-training; 5) prevention, ie, avoiding the excessive focus on tools and techniques; 6) partnering, escaping from island companies, or island territories and departments; 7) caring for the planet by providing green practices/approaches; and 8) an attitude of perfection, which is the "holy grail" for lean businesses and management. ${ }^{21}$ Together, these principles of the lean management philosophy have been presented as means to overcome the initial fifteen industry-centered problems.

Lean management principles, its philosophy or approach, may be applied at several points in health care practices, namely in the redefinition of internal processes, ${ }^{13,19}$ in the standardization of diagnostic systems; ${ }^{20,22}$ in the standardization of work; ${ }^{20}$ in communication processes; ${ }^{10,22}$ in the preparation of preventive programs; $;^{20,22}$ and overall in health care programs ${ }^{23,24}$ aimed at the general public. ${ }^{25,26}$

Among the practices just listed, those most frequently reported are patient flow reorganization and the application of a type of just-in-time approach to processes directly involving the patient. The reason for this is the capacity of these practices to achieve targets imposed by national health care systems with a view to reducing the time spent by patients in hospitals, making it possible to free up beds needed for other patients. ${ }^{10,20}$ Their usefulness is also evident in emergency services, where the application of such practices leads to smooth flow, and also are having an impact on the reduction of resource consumption, accompanied by cumulative patient satisfaction. ${ }^{11,12,14,23,27}$ It is also worth noting that these practices help to eliminate duplication of work, enabling professionals to devote more time to their patients and speeding up treatment and recovery, thereby allowing institutions to put patients first, ${ }^{15}$ at the center of care and focus on the real primary activities of the value chain of a health care provider. Conversely, the practice least often mentioned in the literature is the preparation or the setup of general, multifaceted health programs. This is explained by the wide-ranging nature of such practices that prevent short-term quantification of results, which are mostly reflected in patient well-being and prevention of symptoms or illness. ${ }^{26,28}$

The examples provided in the literature demonstrate the effectiveness and efficiency of applying lean thinking and practices to the health care sector by the excellent results achieved, as shown in several published studies. ${ }^{1,2}$ From the
UK, Canada, or the USA, several examples could be chosen. However, it is much more difficult to find comparable results in non-Anglo-Saxon cultures, and especially in southern Europe, as this paper illustrates. ${ }^{10,13,16,29}$ In short, the main results of the implementation of lean approaches in health care services are improved operating results, an increased quality of the services provided, reduction of waiting times, and increased patient satisfaction - and always accompanied by cost reduction. ${ }^{11,17,20,23,30}$

According to data from the American Society for Quality ${ }^{31}$ the facilities that make the most use of lean principles are operating rooms and emergency services, because the operations and processes that occur there are those where value added is most significant from the patients' perspective. It is ironic to contemplate, and this phenomenon is much more evident in Latin cultures, that when patients are attending an emergency service they know already from the outset that they will have to wait some hours before being seen by a medical doctor. As a result, a number of hospitals, particularly central hospitals, have adopted lean principles as a toolset to reduce problems experienced by emergency services, with excellent results in reducing waiting times and avoiding overcrowding in certain sectors, as already discussed. ${ }^{11-13,14,23,27,30}$

\section{A brief overview of the different types of triage systems}

There are several different types of triage systems where patients are evaluated upon arrival at a health care unit, particularly to emergency services. The Triage by Order of Arrival System (TOAS) is, currently, a system where patients receive care designated by the order of their arrival at the emergency service, without taking severity criteria into account or prioritizing more urgent cases. ${ }^{31}$ The TOAS triage system operates on a "first-come, first-served" basis.

The Triage by Priority System (TPS) is a method used to determine the priority of diagnosis and medical treatment by means of a preliminary clinical assessment based on algorithms that take into account available resources, whereby patients with the most urgent requirements are assisted first. ${ }^{32-34}$

More recently, a new form of care, and also of triage, has become available to patients: telephone care. Initially used for primary health care appointments, this form of care soon became established as a tool with considerable potential and benefits, leading to its expansion to specific facilities such as emergency services. In this setting, algorithm-based Telephone Triage Systems (TTS) were developed that could 
provide a quick and reliable response to patients' questions, involving no physical or psychological disadvantages and greater patient comfort. Additionally, these systems eliminate the need for sometimes difficult and unnecessary patient travel and reduce congestion in face-to-face appointments. ${ }^{35,36}$

Following the exponential rise in the number of Internet users in recent years, the Internet is becoming considered, in parallel with telephone or by itself, as a new channel of communication between health care professionals and patients, and eventually as a triage system as well. The Internet facilitates online chat and practically immediate access to a health care facility with the advantages of enabling and instilling good health care practices; this method of communication/triage, which can be combined with email, will be termed the Online TS. ${ }^{37-40}$ Inspired by lean thinking and management practice, it was in the area of the triage systems that we decided to link the telephone and/or Internet and email approaches to lean practices, studying the viability of the implementation of a new triage system in the emergency department of Portuguese Institute of Oncology (Instituto Português de Oncologia).

\section{Methods}

In line with the objective of the paper and the corresponding case study methodology, ${ }^{41}$ the empirical study was conducted within the emergency service. Instituto Português de Oncologia (IPO), (Oncological Portuguese Institute, Lisbon). For the internal perspective, the sample for semistructured interviews comprised 14 of the 18 nurses who were the professional health care providers in the emergency triage service. During December 2012, each nurse was personally interviewed by the researchers and authors of the present paper. The semistructured interviews, which were based on a previously prepared script, lasted an average of 90 minutes each. The information content thus gathered was subsequently analyzed qualitatively.

For the external perspective, information was gathered by means of a questionnaire-based survey of patients that was divided into three parts. In the first part, questions were addressed to characterize the sample (sex, age, education, with whom patients were living, district of residence, and mean time spent traveling between their home and the hospital). The second part addressed a set of questions about triage systems, both explaining the systems as mentioned previously (email/Online TS, TTS, TPS, and TOAS) and asked for the perceived appropriateness of each triage system for patient needs. Included in this second part of the questionnaire, patients were asked if they have already been exposed to a TTS, and whether the experience and the degree of satisfaction with the solution(s) proposed at that time were adapted, in terms of efficiency and efficacy, to the problems they had presented. The third part of the questionnaire aimed to evaluate the perception and predisposition of the patients to use, in the near future, a remote triage system for oncology purposes. Patients were asked to evaluate a remote triage system as the first of their options. Generally, questions were parameterized in a six-point Likert scale.

The study sample was selected on a convenience basis and comprised 300 patients using the outpatient facility (outpatient appointments, chemotherapy day hospital, treatment room, and emergency service) between December 1, 2012 and January 25, 2013. Although this was not a random sample (which would not be viable, given the impossibility of knowing the population) it enabled us to have confidence in its quality and therefore in the results obtained due to its size, and because it encompasses the range of different circumstances observed within a facility of this kind in indicators such as sex, age, education and place of residence, among others.

The questionnaires were completed by the patients individually or with the assistance of family or a caregiver for those with insufficient independence (eg, because of their impaired condition), to answer the questionnaire unassisted. The collected data were subsequently analyzed using the Statistical Package for the Social Sciences (20st v SPSS; IBM Corporation, Armonk, NY, USA). Univariate descriptive analysis techniques were used to describe the patients' positioning by analyzing the percentage structure of the distribution of answers and calculating summary statistics; in addition, bivariate correlational and inferential analyses provided insight into the relationships among the variables. Thereby a qualitative approach regarding the collaborators (interpretive paradigm and comprehensive/interpretive/ descriptive methods) and a quantitative approach regarding the patients (positivist paradigm and quantitative/more experimental methods) could be unified.

\section{Case study analysis and results Internal perspective}

Table 1 summarizes the results of the interviews conducted with nurses working in the triage emergency service. In addition to the main conclusions, the degree to which each issue was addressed is also indicated, resulting from a qualitative extensive treatment of the semistructured interviews. Consideration of the interviews shows that TOAS, the current triage system used is neither effective nor efficient, and that the nurses involved are unanimous in claiming that for the 
Table I Content analysis of the semistructured interviews

\begin{tabular}{|c|c|c|c|}
\hline Issues addressed & Symbols & \multicolumn{2}{|l|}{ Main ideas/comments of the nurses interviewed } \\
\hline $\begin{array}{l}\text { Assessment of the current } \\
\text { triage system - (triage by } \\
\text { order of arrival) }\end{array}$ & & \multicolumn{2}{|c|}{$\begin{array}{l}\text { Increases patient morbidity (urgent cases have to wait their turn). There is no tool that makes it } \\
\text { possible to focus on the major problems. Neither effective nor efficient. }\end{array}$} \\
\hline $\begin{array}{l}\text { Importance of physical } \\
\text { presence of the patient }\end{array}$ & & \multicolumn{2}{|c|}{$\begin{array}{l}\text { Introduces new degrees of freedom in managing patients' physical presence when questioned about } \\
\text { their clinical situation. Remote triage allows appropriate referral, avoiding unnecessary travel and } \\
\text { excessive use of resources, in particular, human resources. }\end{array}$} \\
\hline Impact of implementation & & Positive aspects & Negative aspects \\
\hline Triage by priority system & & $\begin{array}{l}\text { - Optimizes management of priority situations; } \\
\text { - Allows global overview of the degree of urgency } \\
\text { of all patients; } \\
\text { - Enables patients to estimate waiting times } \\
\text { associated with colors. }\end{array}$ & $\begin{array}{l}\text { - Requires the acquisition of a specific IT } \\
\text { system. }\end{array}$ \\
\hline Telephone triage system & & $\begin{array}{l}\text { - Improves management of admissions; } \\
\text { - Allows planning of care; } \\
\text { - Reduces the number of patients. }\end{array}$ & $\begin{array}{l}\text { - Favors extra difficulties on global } \\
\text { assessments resulting from the emergence } \\
\text { of communication problems; } \\
\text { - Introduces a greater risk of error in the } \\
\text { assessment. }\end{array}$ \\
\hline $\begin{array}{l}\text { Triage by order of arrival } \\
\text { system }\end{array}$ & & $\begin{array}{l}\text { - Does not require an algorithm-based program; } \\
\text { - Increases patient satisfaction. }\end{array}$ & $\begin{array}{l}\text { - Inserts unawareness in clinical situations of } \\
\text { patients admission to triage; } \\
\text { - Introduces negligence risks; } \\
\text { - Increases patients' waiting times for triage. }\end{array}$ \\
\hline Online triage system & & $\begin{array}{l}\text { - Allows fast triage with prior diagnosis; } \\
\text { - Becomes more effective in nonserious situations. }\end{array}$ & $\begin{array}{l}\text { - Increases difficulties of use by patients, } \\
\text { resulting in errors; } \\
\text { - Increases the risk of low uptake by patients. }\end{array}$ \\
\hline $\begin{array}{l}\text { Overall conclusion about } \\
\text { the best triage system for } \\
\text { implementation in the hospital }\end{array}$ & & \multicolumn{2}{|c|}{$\begin{array}{l}\text { The use of a remote triage system in conjunction with a face-to-face triage system appears to be the } \\
\text { most effective and efficient approach. In this case a telephone triage system combined with a priority- } \\
\text { based triage system was appointed as the most appropriate solution for the needs of the hospital. }\end{array}$} \\
\hline
\end{tabular}

initial examination/assessment, the patient does not need to be physically present. This leads to the result that the ideal triage system in this situation is a combination of a remote triage system such as a TTS, and a face-to-face triage system, such as a TPS.

\section{External perspective}

\section{Sample}

The 300 patients who made up the sample were aged between 15 and 87 years (the facility does not accept pediatric patients). The majority of the patients $(64.3 \%)$ were female, with an average age of 52 years old (standard deviation [SD] $=13.0$ years); the average age of the male patients was 57 years ( $\mathrm{SD}=16.2$ years). The educational level of the majority $(48.7 \%)$ of patients corresponded to, at most, compulsory schooling in the Spanish system, or the equivalent of 9 years. Most of the patients lived either with a spouse (38.7\%) or with a spouse and children (33.0\%). Most of the patients resided in the capital district of the country $(73.0 \%)$. Travel time from their home to the institution we studied varied between under 20 minutes and more than 2 hours, the average travel time being 53 minutes ( $\mathrm{SD}=39.2$ minutes). Of the patients who made up the sample, $55.3 \%$ had previously made use of the hospital's emergency service.

\section{Results}

The questionnaire included a presentation and description of the four triage systems (Online TS, TTS, TPS, and TOAS), to which patients were requested to assign a score from one to six (1, totally inadequate; 2 , inadequate; 3 , partially inadequate; 4 , partially adequate; 5 , adequate; 6 , completely adequate).The TTS was given the highest score by the patients (Figure 1). In fact, $79.4 \%$ considered it to be adequate or completely adequate when properly explained, with an average score of 5.0. A similar assessment of the TPS showed that it was also considered adequate or completely adequate by the majority of patients (72.4\%), with an average score of 4.9 (in both cases, when properly explained).

Despite receiving a lower score in comparison with the previous systems, the Online TS also received a relatively good assessment, with an average score of 4.2 , regarded as partially adequate or adequate by $65.2 \%$ of patients. The system with 


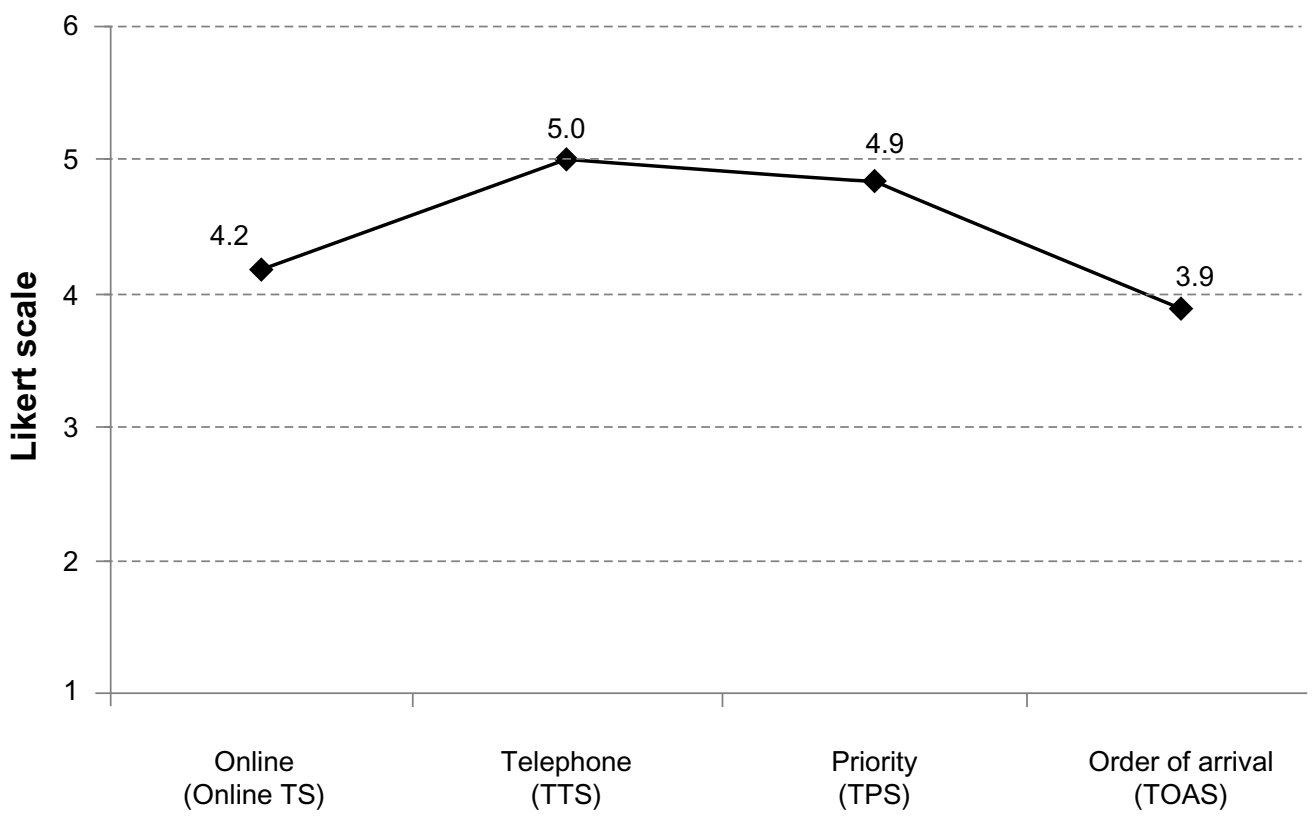

Figure I Assessment of the triage systems (TS) by patients (external perspective): Online (chat room) TS; by telephone (TTS), by priority of urgency (TPS); by order of arrival (TOAS).

Notes: Likert Scale (I to 6). I, totally inadequate; 2, inadequate; 3, partially inadequate; 4, partially adequate; 5, adequate; 6, completely adequate.

the worst assessment was the TOAS, regarded by only $46.2 \%$ of patients as adequate or completely adequate (when properly explained); it was also the system with the highest percentage of replies corresponding to a negative assessment (32.2\%). Nonetheless, it obtained an average score of 3.9 (above the middle of a six-point scale).

Overall, comparing the face-to-face triage systems (TPS and TOAS) with the remote systems (Online TS and TTS) the former received a lower average score (4.4; $\mathrm{SD}=0.953$ and 4.6, SD $=1.029$, respectively). Regarding the TTS, a significant majority of patients have never used it (71.8\%). Because it was not in use in this oncological hospital, patients could have used it in the emergency service of another hospital, perhaps not one with an oncological emphasis. Those patients who had used it were requested to assess the degree to which their problem was resolved, by choosing one of three possible replies: 1) not resolved; 2) partially resolved; and 3) completely resolved. $52.4 \%$ considered their problem to have been completely resolved.

The patients were also asked about their degree of satisfaction with the telephone care and resolution of the problem. To this end, they were asked to provide a score between one and six (1, completely unsatisfied; 6 , completely satisfied). The results showed that $82.3 \%$ of patients awarded the TTS the top two scores of the scale, indicating a high degree of satisfaction (average score, 5.1). In addition, patients' perception of the speed and effectiveness of the TTS in resolving problems was queried, also on a scale from one to six (1, disagree completely; 6 , agree completely), with $63.5 \%$ of patients awarding the top two scores, resulting in an agreement average of 4.8 .

A final set of questions sought to ascertain patients' willingness to use a remote triage system (TTS or Online TS) in future use of the oncological emergency service of the hospital studied. Patients were asked to use a scale of one to six (1, disagree completely; 6 , agree completely) to indicate whether they would be willing to use these triage systems in the future. The results show that patients were more receptive to using the TTS rather than the Online TS in the future. In fact, for the TTS, $67.9 \%$ of patients awarded the top two scores of the scale, with an average of 4.7, while receptivity towards the Online TS was lower (with $44.3 \%$ of patients awarding the top two scores of the scale, with an average agreement value of 3.9).

\section{Factors explaining the use of a TTS}

To understand the factors that might explain a patient's answer concerning the use of a TTS, its relationship with indicators such as sex, age, education, household members, place of residence, travel time, and prior use of the emergency service of the oncological hospital was examined. Inferential analysis was carried out not with the goal of making inferences, because the sample was not a probabilistic one, but simply of ascertaining the magnitude of the effects. See Figure 2 for 


\begin{tabular}{|l|l|}
\hline Symbols & Designation \\
\hline$t$ & Student's $t$ test for independent samples \\
\hline$\chi^{2}$ & Pearson's chi-squared test \\
\hline$\eta$ & Eta coefficient (correlation ratio) \\
\hline Cramer's $V$ & Cramer's coefficient \\
\hline$r$ & Pearson correlation \\
\hline $\mathrm{M}$ & Mean \\
\hline$P$ & Significance or $P$-value \\
\hline
\end{tabular}

Figure 2 Statistical symbols.

identification of the statistical terms. The analysis revealed a significant difference in the average age of the patients, namely between those who had never used the TTS (in other non-oncological hospitals because TTS is not used in any oncological emergency service in the country) and those who have $(t(296)=3.488, P=0.001, \eta=0.513)$, the latter being significantly older (mean, 55.4 years) than the first (mean, 49.1 years). A statistically significant relationship was also found between the use of the TTS and having previously made use of the oncological emergency service, albeit of low intensity $\left(\chi^{2}(1)=16.664, P=0.000\right.$, Cramer's $V=0.236$ ). The percentage of patients who have never used a TTS is significantly larger in the group of patients who have never made use of the emergency service of the oncology hospital that we studied ( $83.6 \%$ versus $62.2 \%)$. No other relationships were significant.

Analysis of the relationship between assessment of the remote triage systems and willingness to use them in the future as a first effort to receive health care revealed a positive correlation of moderate intensity, both for the Online TS ( $r=0.586, P=0.000)$, and for the TTS $(r=0.522$, $P=0.000$ ). In other words, the higher the score assigned to the triage system, the greater the patients' willingness to use it in the future.

The study also sought to ascertain the factors conditioning willingness to use a remote triage system in the future as a first effort to receive health care. To this end, the relationship between willingness to use the TTS and Online TS and the above-mentioned indicators was analyzed. The results obtained showed that when comparing the two groups (the group that had already used an Online TS compared with the group that had not used it in the past), a significant difference appeared (although small) in the willingness to use this triage system in the future $(t(278)=-2.547, P=0.011$, $\eta=0.151)$.

Finally, it was observed that the greater the willingness to use one of the remote triage systems in the future, the greater was the willingness to use the other as well, on the basis of a significant positive correlation with moderate intensity ( $r=0.586, P=0.000$ ) between the two systems (Online TS and TTS).

\section{Discussion}

Analysis of the assessment by the emergency service nurses of the four types of triage presented here - TOAS, TPS, TTS and Online TS - shows that an appropriate solution would be the implementation of a remote triage system in conjunction with a face-to-face triage system. Of the two types of remote triage, the TTS was the most consensual because, by enabling direct contact and real-time replies to patients' questions, it becomes possible to screen and to refer them to the most appropriate facility. This would lead to a reduction in the number of admissions and, in those cases where the patients were required to travel to the facility, it would be possible to prepare for their admission by using the patient's travel time to contact the doctor and organize the procedures to be carried out. This process is of enormous benefit to the facility; however, it requires patients to be informed to use it and also requires proper planning skills.

As regards face-to-face triage systems, the choice was unanimous: the TPS is the most appropriate, enabling an immediate preliminary assessment. On this basis, medical observation can be organized according to the priority of the patient's situation, providing health professionals with an overview of the severity of a patient's condition and at the same time, making it possible to give the patient information about expected waiting time. In brief, implementation of preliminary telephone triage in conjunction with triage by priority allows hospital collaborators (nurses) to anticipate patient numbers and their reasons for attending the emergency service, enabling planning of care and prioritization of observation following admission.

As for the external perspective, our analysis of patients' replies to the questionnaire revealed that the highest-rated triage systems were TTS and TPS. A possible explanation for the fact that the ratings assigned to the various systems were, on average, relatively close, with values between 3.9 and 5, could be that the majority of the patients have never used these systems and replied in accordance with what they perceived to be socially expected and explained by the researchers. Nonetheless, it is interesting to emphasize that the external perspective corresponds with the internal one, which maintains the usefulness of combining a remote triage system (TTS) with one that is a face-to-face (TPS).

Another unexpected conclusion was that the remote triage systems were, on average, rated more highly than the 
face-to-face systems. This is perhaps explained by the low score awarded to the TOAS, revealing dissatisfaction on the part of the patients in relation to the system currently in use in the facility in question, confirming the urgent need for organic restructuring of the facility. This result may also reflect the need felt by the patients for a remote triage system to be formally implemented by the hospital's emergency service, a conclusion reinforced by the statistically significant relationship between patients' assessment of remote triage systems and their willingness to use them in the future.

Although it was awarded the highest score, the TTS had never been used by the majority of patients, a result that reflects unawareness of this resource on the part of the patients. This is validated by the existing relationship between patients who have already made use of the emergency service of the hospital and those who have used TTS triage systems, even if they were used in the context of other hospitals for non-oncological purposes. Other results also point toward the potential of telephone-based initial care. The satisfaction of patients who have already used the service is very high, with over half of all situations having been resolved using this approach. It is also important to note that the vast majority of the patients in the sample reported willingness to use the TTS in the future as a way to obtain health care. These results are similar to those presented in the literature we reviewed, confirming once again the efficiency and effectiveness of this triage system. As regards the Online TS, it can be concluded that although it was not the first choice of either patients or nursing personnel, both are willing to use it in the future.

Despite the high degree of acceptance of the TTS by both employees and patients, it is important to point out the main limitation of the TTS as identified by the present study and also supported by the literature: ${ }^{42,43}$ a higher probability of errors in health professionals' assessment of complaints. This could arise from the difficulty experienced by patients in conveying/describing symptoms, which in urgent or acute situations can compromise patients' safety as compared with face-to-face triage systems.

In the course of this study, certain other limitations were also encountered. These include, in particular, low levels of responsiveness and willingness on the part of patients using the emergency service to complete the questionnaires as a result of their clinical circumstances, which frequently included weakness and acute complaints. It soon became clear that it would be difficult to achieve a suitable sample in a short period of time, as a result of which we chose to expand the scope of the questionnaires, distributing them to all outpatients. This meant that some of the patients who responded to the questionnaire had never made use of the emergency service. This situation was nonetheless felt to be acceptable, given that many of them, despite never having used the emergency service, had benefited somehow from telephone care from other hospitals (the main focus of research) and the remainder were potential users of this facility.

\section{Conclusion}

At a time when priorities are focused on reducing costs and increasing the quality of care that can be provided, the establishment of new approaches that would enable optimization of existing resources and increase patient satisfaction is a mission that is perfectly matched with the principles and philosophy of lean management - which, in general and in everyday language, seeks to achieve more with less. From the outset, this study was able to conclude that the triage system in use, TOAS, is not the most appropriate for this specific facility, on the basis of unanimous results: both nursing personnel in the triage system of the emergency service and the patients who use it are dissatisfied with the system, regarding it as ineffective and inefficient.

In this regard, telephone triage makes it possible to plan and organize the admission of patients to the facility. Indeed, prior knowledge of the symptoms makes it possible to take the necessary steps for a patient's care to begin immediately upon arrival to resolve the problem, avoid waiting times that include the time for triage, arrival of the patient's file, and contact with the medical doctor, among several timeconsuming steps. By reducing the number of admissions to the facility it is believed that all other stages in the process will improve; telephone triage is therefore regarded as a lean practice because the main results that can be obtained thereby are increased customer (patient) and employee (health care personnel) satisfaction with resource optimization. This will result in consistent cost reduction.

Although the study confirmed the efficiency of the TTS, it also highlighted a need for a face-to-face triage system, identifying triage by priority as the most appropriate system for the facility under consideration in the present study. Nonetheless, there is a large gap in the available knowledge regarding implementation of a TTS in conjunction with a TPS in an oncological emergency service. Accordingly, further research is required in order to better understand the consequences for patients and for the institution. However, we firmly believe that the present study can be the first step in the application of a much broader approach to lean thinking in health care facilities, specifically in the hospital 
under consideration. Thinking about triage systems as possible elements of a lean philosophy, constant intervention at the various stages is essential to create maximum value for the patient and, in parallel, to reduce costs.

We therefore also proposed to the institution under consideration an experimental period of implementation of an online TS combined with a TTS, whereby patients are afforded direct chat or email contact with a professional or with auxiliary personnel, who will be able to answer all their questions and/or refer them as appropriate, along with a TTS implementation pilot. After an initial test period, perhaps 3 to 6 months, another evaluation and study should be conducted to assess professionals/auxiliary personnel and patient satisfaction. Benefits and risks of the newly proposed approach should then be reviewed and compared with the present results. At the time of the revised submission of this paper, the hospital was applying a pilot where both approaches were being developed, TTS and Online TS.

\section{Disclosure}

The authors report no conflicts of interest in this work.

\section{References}

1. Hines P, Found P, Griffiths G, Harrison R. Staying Lean: Thriving, Not Just Surviving. Cardiff: Lean Enterprise Research Centre, Cardiff University; 2008.

2. Hines P, Holweg M, Rich N. Learning to evolve: a review of contemporary lean thinking. Int J Osteopath Med. 2004;24(10):994-1011.

3. Jones D, Mitchell A. Lean Thinking for the NHS. London UK: NHS Confederation; 2006. Available from: http://www.leanuk.org/ downloads/health/lean_thinking_for_the_nhs_leaflet.pdf. Accessed September 20, 2013.

4. Young T, Brailsford S, Connell C, Davies R, Harper P, Klein J. Using industrial processes to improve patient care. BMJ. 2004;328(7432): $162-164$

5. Ohno T. Toyota Production System: Beyond Large-Scale Production. Cambridge (MA): Productivity Press; 1988.

6. Womack J, Jones DT. Lean Thinking: Banish Waste and Create Wealth in Your Corporation. London: Simon \& Schuster; 2003.

7. Womack J, Jones DT, Roos D. The Machine that Changed the World: the Story of Lean Production. New York: Harper Perennial; 1991.

8. Dennis P. Lean Production Simplified. 2nd ed. New York: Productivity Press; 2007.

9. Papadopoulos T, Merali Y. Stakeholder network dynamics and emergent trajectories of Lean Implementation Projects: a study in the UK National Health Service. Public Money and Management. 2008;28(1):41-48.

10. Souza LB, Pidd M. Exploring the barriers to lean health care implementation. Public Money and Management. 2011;31(1):59-66.

11. Decker WW, Stead LG. Application of lean thinking in healthcare: a role in emergency departments globally. Int J Emerg Med. 2008;1(3): 161-162.

12. Banerjee A, Mbamalu D, Hinchley G. The impact of process re-engineering on patient throughput in emergency departments in the UK. Int J Emerg Med. 2008;1(3):189-192.

13. Ng D, Vail G, Thomas S, Schmidt N. Applying the Lean principles of the Toyota Production System to reduce wait times in the emergency department. CJEM. 2010;12(1):50-57.
14. King DL, Ben-Tovim DI, Bassham J. Redesigning emergency department patient flows: application of Lean Thinking to health care. Emerg Med Australas. 2006;18(4):391-397.

15. Green I. Drive for success. Nursing Standard. 2007;21(38):62-63.

16. Lummus RR, Vokurka RJ, Rodeghiero, B. Improving quality through value stream mapping: a case study of a physician's clinic. Total Quality Management and Business Excellence. 2006;17(8): 1063-1075.

17. Battaglia F. Hospitais dos EUA melhoram indicadores de gestão com Sistema Lean. Brazil [United States Hospitals are improving their management indicators with Lean Approaches]: Lean Institute Brasil; 2010. Available from: http://www.lean.org.br/artigos/128/equipe.aspx. Accessed September 20, 2013. Portuguese.

18. Castle A. Lean thinking on the wards. Nursing Standard. 2007;22(8): $16-18$.

19. Miller D. Going Lean in Health Care. IHI Innovation Series White Paper. Cambridge (MA): Institute for Healthcare Improvement; 2005. Available from: http://www.ihi.org/knowledge/Pages/IHIWhitePapers/ GoingLeaninHealthCare.aspx. Accessed September 21, 2013.

20. Kim CS, Spahlinger DA, Kin JM, Billi JE. Lean health care: what can hospitals learn from a world-class automaker? J Hosp Med. 2006;1(3):191-199.

21. Hines P. The Principles of the Lean Business System. Available from: http://www.atem.org.au/uploads/publications/-The_Principles_of_The Lean_Business_System.pdf. Accessed September 20, 2013.

22. Raab SS, Grzybicki DM, Sudilovsky D, Balassanian R, Janosky JE, Vrbin CM. Effectiveness of Toyota process redesign in reducing thyroid gland fine-needle aspiration error. Am J Clin Pathol. 2006; 126(4):585-592.

23. Meyer H. Life in the lean lane: performance Improvement at Denver Health. Health Aff (Millwood). 2010;29(11):2054-2060.

24. Smith J. Redesigning health care: Radical redesign is a way to radically improve. BMJ. 2001;322:1257-1258.

25. Joosten T, Bongers I, Janssen R. Application of lean thinking to health care: issues and observations. Int J Qual Health Care. 2009;21(5): 341-347.

26. Badamgarav E, Weingarten SR, Henning JM, et al. Effectiveness of disease management programs in depression: a systematic review, $A M$ J Psychiatry. 2003;160(12):2080-2090.

27. Weinstock M. Storyboard. How one hospital slashed ED waits. Hosp Health Netw. 2007;81(12):22.

28. Joosten TC, Bongers IM, Meijboom IB. Care programmes and integrated care pathways, Int J Health Care Qual Assur. 2008;21(5): $472-486$.

29. Merriam G. Efficiency system revs up health care. USA: Missoulian; 2004. Available from: http://missoulian.com/news/local/efficiencysystem-revs-up-health-care/article_fd3508f5-42d 7-5225-85085ce13194e1fe.html. Accessed September 20, 2013.

30. Holahan J. Reduce Emergency Department wait with lean management State Health Watch. 2010;17(3):12.

31. Graban M. Lean Hospitals: Improving Quality, Patient Safety, and Employee Satisfaction. New York: Productivity Press; 2012.

32. Crespo de Carvalho J, Ramos T. Logística na Saúde, [Healthcare Logistics]. Lisbon, Portugal: Edições Sílabo; 2009. Portuguese.

33. Wuerz RC, Milne LW, Eitel DR, Travers D, Gilboy N. Reliability and validity of a new five-level triage instrument. Acad Emerg Med. 2000;7(3):236-242.

34. Dong SL, Bullard MJ, Meurer DP, Blitz S, Holroyd BR, Rowe BH. Emergency triage: comparing a novel computer triage program with standard triage. Acad Emerg Med. 2005;12(6):502-507.

35. Beaver K, Tysver-Robinson D, Campbell M, et al. Comparing hospital and telephone follow-up after treatment for breast cancer: randomised equivalence trial. BMJ. 2009;338:a3147.

36. Huang J. Comparison of the effectiveness of different preoperative screening methods: telephone interview versus hospital visit. The Internet Journal of Anaesthesiology. 2003;7(2). Available from: http:// ispub.com/IJA/7/2/11447. Accessed September 20, 2013. 
37. Frank SR. Digital health care-the convergence of health care and the Internet. J Ambul Care Manage. 2000;23(2):8-17.

38. Pinnock H, Hoskins G, Neville R, Sheikh A. Triage and remote consultations: moving beyond the rhetoric of access and choice. $\mathrm{Br} \mathrm{J}$ Gen Pract. 2005;55(521):910-911.

39. Leong SL, Gingrich D, Lewis PR, Mauger DT, George JH. Enhancing doctor-patient communication using email: a pilot study. $J$ Am Board Fam Prac. 2005;18(3):180-188.

40. Car J, Sheih A. Email consultations in health care: 1 - scope and effectiveness. BMJ. 2004;329(7463):435-438.
41. Yin RK. Case Study Research: Design and Methods. 4th ed. Applied social research methods series; v.5. Thousand Oaks, CA: Sage Press; 2009.

42. McKinstry B, Hammersley V, Burton C, et al. The quality, safety and content of telephone and face-to-face consultations: a comparative study. Qual Saf Health Care. 2010;19(4):298-303.

43. Bunn F, Byrne G, Kendall S. The effects of telephone consultation and triage on healthcare use and patient satisfaction: a systematic review. Br J Gen Pract. 2005;55(521):956-961.

\section{Publish your work in this journal}

Risk Management and Healthcare Policy is an international, peerreviewed, open access journal focusing on all aspects of public health, policy, and preventative measures to promote good health and improve morbidity and mortality in the population. The journal welcomes submitted papers covering original research, basic science, clinical \& epidemio- logical studies, reviews and evaluations, guidelines, expert opinion and commentary, case reports and extended reports. The manuscript management system is completely online and includes a very quick and fair peerreview system, which is all easy to use. Visit http://www.dovepress.com/ testimonials.php to read real quotes from published authors. 